\title{
The Content of Sexual Fantasies for Sexual Offenders
}

\author{
Dion G. Gee, ${ }^{1,4}$ Grant J. Devilly, ${ }^{2}$ and Tony Ward ${ }^{3}$
}

Although the phenomenon of sexual fantasy has been extensively researched, little contemporary inquiry has investigated the content of sexual fantasy within the context of sexual offending. In this study, a qualitative analysis was used to develop a descriptive model of the phenomena of sexual fantasy during the offence process. Twenty-four adult males convicted of sexual offences provided detailed retrospective descriptions of their thoughts, emotions, and behaviors before, during, and after their offences. Using Grounded Theory, a model was developed to elucidate the content and themes of sexual fantasy for sexual offenders, as well as the way fantasy content was used in the process of sexual offending. The Sexual Fantasy Content Model (SFCM) comprises of three higher-order (level 1) and five secondorder (level 2) categories that describe the content of sexual fantasy across the offence process. The level 1 categories are general sexual fantasy, nonspecific offence fantasy, and offence-specific fantasy, whereas the level 2 categories included demographic, behavioral, relational, situational, and self-perceptual considerations. The strengths of the SFCM are discussed and its clinical implications are reviewed.

KEY WORDS: sexual fantasy; content; sexual offender; Grounded Theory.

\section{INTRODUCTION}

Extensive research has demonstrated that people who have never participated in sexually aberrant behavior entertain sexual fantasies that involve deviant sexual imagery (Arndt, Foehl, \& Good, 1985; McCollaum \& Lester, 1994; Person, Terestman, Myers, Goldberg, \& Salvadori, 1989; Sue, 1979; Templeman

\footnotetext{
${ }^{1}$ Department of Psychology, University of Melbourne, Victoria, Australia.

${ }^{2}$ Centre for Neuropsychology, Swinburne University, Victoria, Australia.

${ }^{3}$ School of Psychology, Victoria University of Wellington, Wellington, New Zealand.

${ }^{4}$ To whom correspondence should be addressed at Thornford Park-Blenheim, Crookham Common, Thatcham, Berkshire RG19 8ET, England; e-mail: dion@forensicpsych.co.nz.
} 
$\&$ Stinnett, 1991). The endorsement rates of such sexual fantasies within community samples vary from $3 \%$ in one sample of women (Hunt, 1974) to $61.7 \%$ in a sample of adult males (Crepault \& Couture, 1980).

As with general sexual fantasies, the concept of deviant sexual fantasy remains contentious (for a review see Leitenberg \& Henning, 1995). Nonetheless, like fantasy more generally (Singer, 1966), deviant fantasies can be construed as imaginative processes accompanied by a withdrawal from the immediate demands of the external world and a narrowing in focus of an individual's internal world. Such processes allow an individual to create an elaborate, emotionally anchored, mental picture which has its origins in daydreaming, and involves erotica that creates or intensifies sexual arousal (Carlson \& Havelock-Coleman, 1977; Crepault \& Couture, 1980; Mednick, 1977; Rokach, 1990). However, unlike general sexual fantasy, deviant sexual fantasies may contain themes involving the intentional infliction of harm in a sadistic or otherwise sexually aggressive way (Prentky et al., 1989) or, alternatively, they may contain themes that depict illegal and/or socially unacceptable behaviors. In light of this definition, Hazelwood and Warren (1995) have also posited that sexual fantasies are comprised of behavioral, relational, perceptual, and demographic elements.

Together with the multicomponent nature of fantasy, researchers have also demonstrated that the content of sexual fantasy is highly dependent on what an individual reads, sees, hears, and directly experiences (Jones \& Barlow, 1990; Leitenberg \& Henning, 1995), and varies as a function of past experiences, cognitive style, personality, and an individual's level of creativity (Briere, Smiljanich, \& Henschel, 1994; Mednick, 1977; Reich, 1993; Rokach, 1990). Four overarching content categories of sexual fantasy have been observed (Arndt et al., 1985; Crepault, Abraham, Porto, \& Couture, 1976; Meuwissen \& Over, 1991; Plaud \& Bigwood, 1997; Smith \& Over, 1987, 1991; Wilson \& Lang, 1981): conventional homosexual or heterosexual imagery with past, present, or imaginary lovers who are usually known to the person; scenes expressing sexual power and irresistibility; fantasies involving somewhat varied or "forbidden" sexual imagery; and submission-dominance scenes. Although there is uniformity in themes between the genders, males tend to endorse most fantasies at a higher rate than females (for a review see Leitenberg \& Henning, 1995).

Further research has suggested that the content of male sexual fantasy can be characterized as active (Iwawaki \& Wilson, 1983; Mednick, 1977; Wilson \& Lang, 1981; Zimmer, Borchardt, \& Fischle, 1983), impersonal, and aggressive/poweroriented (Pitcher \& Prelinger, 1963; Rokach, 1990; Wagman, 1967), although both male and female nonoffenders entertain fantasies of forcing sex onto someone (e.g., Arndt et al., 1985; Person et al., 1989; Sue, 1979). Males have also been seen to report higher levels of masochistic fantasy and to exhibit a greater tendency to fantasize about behavior outside "social norms" (McCollaum \& Lester, 1994; Person et al., 1989). 
Studies have also found that large numbers of university students (21\%) acknowledge being sexually attracted to children on occasions (Briere \& Runtz, 1989), that $61.7 \%$ of the general male population reported sexual fantasies about a young girl, whereas fewer reported fantasies about raping a woman (33\%), being humiliated $(11.7 \%)$, bestiality $(5.3 \%)$, or sexual activity with a young boy $(3.2 \%$, Crepault \& Couture, 1980). High numbers of surveyed participants also admitted to recent sexual thoughts about having sex with girls under the age of $15(17 \%)$ or under $12(5 \%)$, voyeuristic fantasies (54\%), and exhibitionistic thoughts $(7 \%$; Templeman \& Stinnett, 1991). In summary, studies report that "normal" men engage in fantasy that are, in part, controlling, sadistic, and/or contravene cultural expectancies.

\section{THE CONTENT OF SEXUAL FANTASY IN SEXUAL OFFENDING}

A large body of research has attempted to elucidate the role of sexual fantasy in sexual offending, with many researchers expressing concern over the potential for fantasy to facilitate action (Badcock, 1997; Hazelwood \& Warren 1995; Looman, 1995; Prentky et al., 1989). Numerous researchers have also highlighted the potential importance of fantasy in sexual offences (see Drieschner \& Lange, 1999; McMurran, Hodge, \& Hollin, 1997; Pithers, 1990; Ward \& Hudson, 2000; Ward \& Siegert, 2002), as well as its potential significance in the etiology of sexual orientation (Storms, 1981). Despite these concerns, contemporary inquiry lacks a fully integrated theoretical framework to conceptualize the complexity of sexually aberrant behavior (Ward, 2000; Ward \& Hudson, 1998b), with a number of researchers suggesting that the results of previous investigations addressing the role of sexual fantasy in aberrant sexual activity have a limited scope due to methodological considerations (Baumgartner, Scalora, \& Huss, 2002; Langevin, Lang, \& Curnoe, 1998; Leitenberg \& Henning, 1995).

Early research demonstrated that a high proportion of male sexual offenders reported deviant sexual fantasies, particularly those related to their paraphillic activities (75\%; McGuire, Carlisle, \& Young, 1965). This is even more prominent in specific behaviors such as sexual aggression (80\%; Burgess, Hartman, Ressler, Douglas, \& McCormack, 1986) and serial rape (95\%; Burgess, Hazelwood, Rokous, Hartman, \& Burgess, 1988). Research conducted by Langevin et al. (1998) revealed that most sexual offenders reported having nondeviant sexual fantasies involving physically mature females, and some $(33.3 \%)$ reported having deviant fantasies involving children, or other deviant sexual activities. Research by Looman (1995) has shown that child molesters (57\%) fantasize about children under the age of 12 more than rapists or nonsexual offenders. Such fantasies are frequently preceded by negative affective states in most sexual offending populations (e.g., Neidigh \& Tomiko, 1991). 
Previous work has also indicated that the presence of sexual fantasies in child molesters is significantly related to the gender of the actual victim. Looman (1997) reported that while $83 \%$ of offenders whose victims were male reported deviant sexual fantasies of children, only $19 \%$ of those with female victims entertained such fantasies. This study also found that those offenders who had established a "friendship" with their victim were more likely to report entertaining sexual fantasies involving children.

Studies have also shown that polyvariant males (men with more than one sexually variant behavior) endorse all types of fantasy at higher rates than sadomasochistic males and fetishists, respectively (Wilson, 1988). Further, as one would expect, child molesters report experiencing higher frequencies of exploratory and intimate fantasies than nonsexual offenders (Baumgartner et al., 2002). It has also been recently suggested (Gee, Hudson, \& Ward, 2003) that sexual offenders who attend treatment programs and those who elect not to do not differ on rates of fantasy, with both groups reporting the highest frequency of sexual fantasy for intimate, followed by exploratory, impersonal, and sadomasochistic sexual fantasy themes.

The goal of the present research was to construct a descriptive, empirically grounded model of the content of sexual fantasy for sexual offenders as they progress through the offense chain. The aim was to incorporate an offender's thoughts, feelings, and behaviors in the pre-, intra-, and postoffence period into a model, as well as to elucidate the themes and specific sexual fantasy content evident during the process of sexual offending. It is anticipated that such datadriven, microlevel investigation at this early stage of theory development may help to provide a clearer description of the content and themes of fantasy in sexually aberrant behavior.

\section{METHOD}

\section{Research Participants}

Research participants comprised 24 male sexual offenders whose index offence (i.e., the most recent offence), resulted in a conviction and subsequent incarceration in a Victorian Correctional Facility. For the purposes of the study, the index offence was required to be sexual in nature, as defined under Pt. 1 Div. 1 Subdiv. (8A), through to (8E) of the Crimes Act (1958). Specifically, these offences included rape, indecent assault, assault with intent to rape, incest, sexual offences against children, sexual offences against people with impaired mental functioning, and other sexual offences. By using the legal definition of sexual offending, the present study utilized a clear-cut criterion for establishing participant inclusion. 
In an attempt to obtain a representative cross-sectional sample of the sexual offender population, participants were recruited from three locations. Nine individuals came from the community-based sexual offender program attached to Victoria's prison-based sexual offender treatment program at Ararat Prison; 11 participants came from the Ararat prison sexual offender treatment program; and a community-based forensic psychiatry setting supplied the remainder of the participants $(n=4)$.

The mean age of the participants in the present study was 45 years $(S D=$ 10.4 years, range 25-62 years). The majority of the 24 participants were Australian $(n=22)$, and 13 were either married or in a de facto relationship at the time of their offending. Eight participants stated that they were living alone at the time of their offence/s, most $(n=22)$ were employed, self-employed or in full-time study at the time of their offence/s, and the education level ranged from year-3 (about 9 years of age) up to a university education or trade certificate. Six participants had a history of alcohol abuse, 1 participant had a history of drug abuse, and 2 participants had a history of abusing both alcohol and drugs.

Thirteen participants had a previous criminal record. Three participants had previous convictions for sexual offences against adults, whereas 4 participants had prior convictions for sexual offences against children. In addition, 5 of these 13 participants had previously breached a court order and/or violated their parole conditions.

The mean age at first conviction for any criminal offence was 28 years ( $S D=12.2$ years, range $12-54$ years). The mean age at which the participants commenced their "index" set of offences was 31 years $(S D=8.2$ years, range 1649 years), and the mean duration of these index offences was 5.3 years $(S D=8.2$ years, range 1 day-30 years). The majority of participants were serving their first term of imprisonment $(n=19)$, with the mean length of the longest term of imprisonment (including current sentence) being 6.2 years $(S D=5.2$ years, range 0.5-20 years).

The majority of participants had committed sexual offences against children $(n=20)$. The remainder of the participants had committed sexual offences against adults. Fourteen participants had abused exclusively female victims, 7 participants had abused exclusively male victims, whereas 3 participants abused both male and female victims. The 4 participants who had abused adult victims did so against females. For 19 participants the victim of the abuse was known to the offender in some way, though some participants had offended against more than one group of victim.

Although all participants committed a hands-on offence, the nature and intrusiveness of the offence behavior varied across the sample, some performed by the offender and some where the offender had the victim perform the acts on either themselves or on the offender. Eight of the participants committed their sexual offences exclusively in their own home, whereas a further 7 participants had offence 
locations outside their own home (e.g., camp, public swimming pool, or school). The remaining 9 participants had offence locations that were exclusively outside of their own home.

\section{Measurement}

The goal of Grounded Theory is to build a theory based upon the interpretation of data. Grounded Theory has been conceptualized as "a process of constantly moving back and forth between the data and developing theory such that the emergent theory itself directly guides data gathering through a process of coding and theoretical sampling procedures" (Mace, 1998, p. 71). Thus, the developing theory is "grounded" in data. It is "discovered, developed and provisionally verified through systematic data collection and analysis of data" (Strauss \& Corbin, 1990, p. 23).

Grounded Theory generation typically progresses through a systematic set of procedures, which begins with concepts being inductively derived from an initial set of qualitative descriptions. These concepts are then coded into provisional categories, which in turn leads to the collection of further descriptions, or data. The process of coding involves conceptualizing the data into discrete parts or meaning units (a meaning unit is a distinct idea in the context of the study), then examining, comparing, reconceptualizing, and sorting them into categories (Rennie, Phillips, \& Quartaro, 1988; Strauss \& Corbin, 1990). During this process, systematic comparisons are used to offset bias, and aid in the development of broader categories (Wilson, Ward, \& Bakker, 1999).

The next step is the deduction of predictions, or hypotheses concerning the ability of the provisional categories to account for new protocols. If the existing categories fail to accommodate the new data, new categories are formulated and the process continues. This modification and refinement of categories and subcategories continues until saturation. Saturation occurs when all new data are effectively coded into the existing categories without requiring any new categories, properties, or relationships (Ward, Fon, Hudson, \& McCormack, 1998). The researcher then draws links between the categories/components and further refines the model until the theory becomes explicit. It is usually at this stage that the researcher makes quantitative appraisals of the data (Wilson et al., 1999).

Fantasies involve private experiences and, consequently, are phenomena that are difficult to measure accurately, particularly when the content of those fantasies relate to aberrant activities. Therefore, a semistructured interview was constructed and utilized to obtain information in relation to offenders' fantasies (i.e., the fantasy script), the use of fantasy (i.e., mental simulation), and to elicit any patterns of criminal activity. The aspects of fantasy that the interview assessed included, but was not limited to, relationship to masturbation; themes and content of fantasy (behavioral, demographic, etc.); role in offending; structure of fantasy (frequency, 
duration, clarity, context, etc.); sources of material for fantasy; function of fantasy (arousal, affect regulation, etc.); changes in fantasy over time; and fantasy escalation. The interview also aimed to elicit information in relation to the offence behavior chain.

\section{Procedure}

The aim of the semistructured interview was to explore the themes and content of fantasy across the process of sexual offending, and to gather descriptive data with respect to this process. The interview guide was composed of a series of open-ended questions, accompanied by a set of more specific questions to elicit the necessary information if this had not emerged spontaneously. The questions were designed to probe for, among other things, fantasy themes, changes in fantasy content, and the more specific elements of sexual fantasy. That is, the behavioral component, the situational component, the relational component, the demographic component, and the perceptual component. The above areas of questioning were explored for the periods before, during, and after the offence.

As is typical during Grounded Theory, the method of constant comparison (i.e., where emergent patterns in the data direct future sampling procedures; Henwood \& Pidgeon, 1992) resulted in some of the initial interview questions becoming redundant, whereas others were elaborated. In other words, as themes became more prominent for certain participant types (e.g., voyeuristic fantasies during the offence chain for those under 30-years-old vs. those over 30-years-old), sampling strategy and interview questions were adapted to assess for differences in these themes for different participants. This meant that data categorization and analysis directed the emerging theory.

\section{Reliability and Validity}

The potential unreliability of self-reported information was addressed through a number of means. All interviews were conducted face-to-face by the same researcher, establishing rapport and facilitating information gathering. Furthermore, all participants were frequently reminded that the research was not part of their treatment, that all information was confidential and that they could withdraw at any stage. Finally, all participants had freely consented to the research. In light of these safeguards, it was believed that participants would be less likely to lie, as they would have gained little from doing so.

In line with the recommendations of Lincoln and Guba (1985), file reviews allowed for the triangulation of data, and provided a means of assessing the reliability of the information supplied during the interview process. Where possible, this information was also checked (confidentially) against information supplied 
by the therapists working in the sexual offender treatment programs. This process was conducted subsequent to all contact with a specific participant, to avoid the possibility of contaminating the interview.

\section{Analysis}

As is recommended when using the Grounded Theory method, analysis of the interview transcripts occurred concurrently with the data collection process. Each interview was transcribed and the data was then entered, stored, and analyzed in QSR: NUD*IST-4 (Qualitative Solutions and Research, 1998). This software is a statistical application for development, support, and management of qualitative data analysis projects. It allows for the flexible handling of text data (such as client feedback) and allows for this qualitative data to be entered, coded, and then analyzed quantitatively.

\section{RESULTS}

\section{Interrater Reliability Check}

An independent evaluator rated a random selection of $33 \%$ of the interviews. He was a psychologist specializing in sexual offender therapy, but who had no prior knowledge of the research methodology, or expertise in Grounded Theory. This check revealed an average agreement of $85 \%$ between the independent evaluator and the researcher in terms of meaning unit identification, with reliability ranging from 83 to $88 \%$. (The acceptable level for rater agreement was set at $80 \%$ in line with conventions in psychology.) The remaining variance was explained by both undercoding (i.e., the researcher had divided some meaning units at a finer level than the independent evaluator) and overcoding (i.e., the independent evaluator had divided some meaning units at a finer level than the researcher).

\section{Sexual Fantasy Content Model}

The analysis of the interview transcripts resulted in the construction of the Sexual Fantasy Content Model (SFCM), which identifies the themes and content of sexual fantasy across the process of sexual offending. At its most abstract, the SFCM suggests that the majority of sexual offenders experience fantasies with sexual content at some point in their lives. However, for a small proportion of sexual offenders $(n=2)$, it appeared that sexual fantasy played little or no part in everyday experiences.

The higher order (level 1) themes are general sexual fantasy and offencefocused fantasy (both nonspecific and offence specific), whereas the second order 


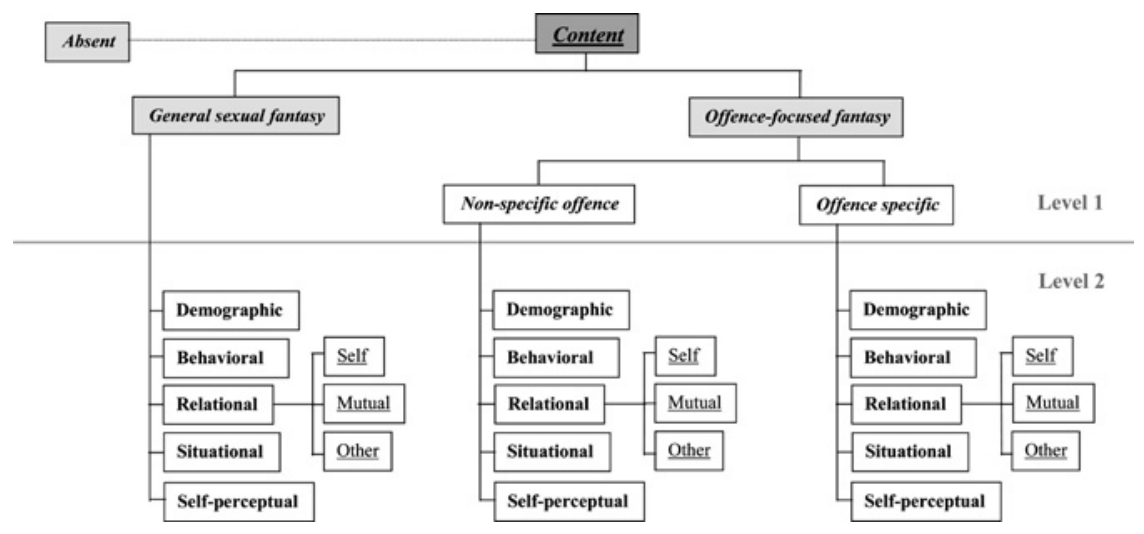

Fig. 1. Key facets of the SFCM.

(level 2) categories included demographic, behavioral, relational (subcategories of which included self, mutual, other), situational, and self-perceptual contents (see Fig. 1).

\section{Level 1}

The SFCM distinguishes between two broad types of sexual fantasy, general and offence-focused. General sexual fantasy refers to fantasy themes that, although being sexual in nature, are unrelated to sexual offending behavior (e.g., "I had fantasies of oral sex, anal sex with friends as I grew up"). All of the participants who reported the use of sexual fantasy $(92 \%)$ reported using this type of fantasy theme. The sexual fantasies evident in this category varied from consensual sexual intercourse with a partner to more culturally unacceptable themes involving voyeurism, mate swapping, and bestiality (e.g., "I thought this could be arousing having sex with an animal, I thought what animal it could be"). Fantasies in this category comprised both purely sexual themes, as well as the more emotionally arousing themes that often accompany sexual activity (e.g., "so the images are of the closeness I enjoyed with [partners name], cuddling and resting in bed together, just being together").

The category of offence-focused fantasy describes those fantasies that contain sexually deviant material that, if acted out, would legally constitute a sexual offence. There are two subtypes of this fantasy, nonspecific offence fantasy and offence-specific fantasy. Nonspecific offence fantasy refers to those fantasies that relate to general aberrant activities rather than to a specific offence (e.g., "I had fantasies about young girls, but not anyone in particular"). Seventy-five percent of the current sample indicated that they had engaged in this form of sexual fantasy. Offence-specific fantasy is conceptually distinct from nonspecific offence fantasy, 
because the themes in this type of fantasy refer to specific offence characteristics. That is, this subcategory of sexual fantasy often involves specific victim characteristics (e.g., "I think that I had thoughts about this particular boy"), and/or the acting out of specific offence behaviors with a victim (e.g., "I had thoughts of doing oral sex with the first victim"). All participants who reported the use of sexual fantasy $(92 \%)$ indicated that they entertained sexual fantasies with offence specific content.

\section{Level 2}

As the SFCM moves from an abstract (Level 1) to a more fine-grained analysis of the content of sexual fantasy (Level 2), it distinguishes between five subcategories of sexual fantasy content. That is, demographic, behavioral, relational, situational, and self-perceptual characteristics. Although it is acknowledged that each of these five subcategories is independent, their combination often determines the general theme of a sexual fantasy.

The demographic subcategory refers to the demographic characteristics of the individuals present within the offender's sexual fantasy. Specifically, this subcategory delineates the gender, age, and biosocial relationship (i.e., the biological or social relationship) between the individuals present in the fantasy. These often mirrored real life situations, but during some fantasies, the characteristics were altered or distant abstractions of real life situations (e.g., "I had thoughts about my step-daughter, but in my head she was a lot older, she was an adult"; see Gee, Ward, Belofastov, \& Beech, 2003).

The second subcategory, that is behavioral characteristics, delineates the sexual activity that transpires in the offender's fantasies. Fantasized behaviors were extremely diverse, ranging from the more common (e.g., "my fantasies were always of just consensual sex, in the missionary position") through the experimental (e.g., "I thought it would be nice to fuck her up the arse, from behind"), to the more bizarre and/or deviant (e.g., "I had thoughts of what it would feel like to have someone urinate inside of me... like one of the boys").

The relational subcategory refers to the interpersonal context of the fantasy. Fantasies varied in how the individual engaging in the fantasy perceived the interplay between the various parties of the fantasy. This variation resulted in three distinct interpersonal foci: mutual, self, and other. Some fantasies had a mutual focus, where the individual engaging in the fantasy gave consideration (albeit distorted) to the perspectives of all parties in the fantasy. This meant that in some instances all of the parties within the fantasy were perceived as actively participating in, and enjoying the experience (e.g., "In my fantasies they will always be a mutual thing, they would have to be into it, that was a reflection in the actual offences, it had to be a mutual thing"). During self instances, fantasies were more narrowly focused, with the person engaging the fantasy concentrating 
purely on himself and meeting his needs (e.g., "I thought about what I wanted, what would be pleasurable for me"), or solely on the other parties within the fantasy (e.g., "I thought I could give her a really good time, she would really enjoy herself, it wasn't about me").

The fourth subcategory of fantasy, termed situational, relates to the situational context of the fantasy. This subcategory details when and where the sexual fantasy was taking place (e.g., "I think my thoughts were generally that it would occur in a bedroom and be at night"). Although this component of fantasy was evident less often in the sexual fantasies of the participants, those fantasies that did contain a situational component varied in complexity. Some sexual fantasies had a more traditional and/or loosely defined situational context (e.g., "we were usually in my bed," "you know, around the house and that"), whereas others had a more elaborate, descriptive, and/or unusual situational context (e.g., "we were in an open field on a sunny day with a blanket and a picnic ... she was not wearing any panties ... I had brought along many sex toys").

The fifth subcategory of fantasy content, self-perceptual, refers to how the individual perceived himself during a particular fantasy (e.g., "I am in control, she is doing everything I am telling her to do"). Although this subcategory of fantasy content was present less often than the other four subcategories, in those situations where it was present, it appeared to be strongly linked to an offender's desire to revisit the particular fantasy. This was especially the case if the offender did not perceive himself as being in control of a situation in his fantasy.

\section{Content Profile}

Although the majority of participants in the sample entertained all three types of sexual fantasy theme (i.e., general sexual fantasy [92\%], nonspecific offence fantasy [75\%], and offence-specific fantasy [92\%]), the use of each theme appeared dependant on which phase of the offence process the individual was describing at the time.

During the historical phase (i.e., childhood recollections, important life events, first sexual fantasies, and the period prior to first offence) 14 participants $(58 \%)$ reported engaging in sexual fantasy. All individuals who reported sexual fantasies during this phase utilized general sexual fantasy content. These themes incorporated all of the level 2 categories of sexual fantasy content. Together with general sexual fantasy, a small number of individuals entertained nonspecific offence fantasies (17\%), although they were generally limited in detail regarding the level 2 categories of fantasy content. Two participants (8\%) also reported engaging in fantasies that contained offence-specific themes from an early age. One of these individuals was a "predatory rapist," whereas the other individual would meet the $D S M-I V-T R$ criteria for pedophilia. 
As an offender moved through the phases of the initial offence chain (Laws, Hudson, \& Ward, 2000), general sexual fantasy themes gradually declined, whereas offence-specific themes increased steadily. The initial offence brought the cessation of both general sexual fantasy and nonspecific offence fantasy themes. Although general sexual fantasy was seen to reemerge in later phases of the offence cycle, nonspecific offence fantasy themes appeared to be restricted to the early phases of the initial offence cycle. Offence-specific fantasy was the only fantasy content that was present at the time of the initial offence. Although 14 individuals $(58 \%)$ reported engaging in this type of sexual fantasy, the comprehensiveness of their fantasies reduced considerably. That is, only the behavioral category of level 2 was evident at the time of the offence. Similarly, during the initial postoffence period sexual fantasy themes were restricted to offence specific content, with 8 individuals $(33 \%)$ reporting this type of fantasy theme.

The beginning of the relapse cycle/s (i.e., offence chain/s that relate to subsequent offending) evidenced the reemergence of both general sexual fantasy and offence specific fantasy themes. Although general sexual fantasy reemerged at a level similar to that of the historical phase, the majority of offenders with a relapse offence entertained offence-specific fantasy themes across the various phases of the relapse offence $(75-86 \%)$. Of significance, the relapse phase also brought a qualitative escalation in all five of the level 2 categories of sexual fantasy. An example of this was the shift in the behavioral content toward more hands-on behaviors, or the incorporation of more bizarre and/or forceful experiences into offence-focused fantasies. Although the actual relapse offence/s was again seen to coincide with a narrowing in fantasy to offence specific themes, $75 \%$ of the sample reported engaging in such fantasies. However, unlike the initial offence, those fantasies that were present at this stage were often comprehensive (i.e., they contained all of the level 2 categories). In other words, in the build-up and during relapse, the fantasies gained detail, intensity, and broadened in scope. During this stage a small group of offenders also engaged in offence-specific fantasy but then actively substituted one or more of the level 2 categories for general sexual fantasy characteristics. To illustrate, "I would be having sex with the victim, but I would put my wife's head on the victim, like imagine it was my wife" (see Gee et al., 2003 for more detail). Similar to the initial postoffence period, the postrelapse stage of the cycle was generally devoid of sexual fantasy.

The postoffending phase brought the cessation of offence behavior, either because the offence behavior was detected, or the offender made a conscious decision to abstain from further offending. However, $80 \%$ of participants reported some form of sexual fantasy during this phase. Both general sexual fantasy themes and offence-specific fantasy themes reemerged at this time $(63 \%$ and $79 \%$ respectively). This reemergence appeared to coincide with the general constriction of an offender's potential sexual outlets (usually because of incarceration, or because of relationship problems that stemmed from the offending behavior). An important 
feature of this phase was the high proportion of offenders who actively attempted to inhibit offence-specific fantasy themes. This occurred either because the offender had appraised such fantasies as causal in their offending and therefore wished to avoid them, or because such fantasies reminded them of the resultant negative consequences of the offence behavior (for themselves, the victim/s, and/or both).

The final phase of the offence process relates to an offender's current situation (which may or may not have involved incarceration) and his ideas about the future. During this phase, the most significant mediator of sexual fantasy appeared to be the presence of a sexual offender treatment program. This appeared to significantly reduce an offenders' engagement in all forms of sexual fantasy. However, those offenders that did entertain general sexual fantasy (42\%) during this phase, and the few that continued to engage offence-specific fantasy themes $(21 \%)$, incorporated all five level 2 categories into their sexual fantasy content.

\section{DISCUSSION}

The salient facets of the SFCM support and potentially extend previous research. The first of these features is the notion of "offence-focused fantasy." As highlighted by Leitenberg and Henning (1995), the concept of deviant sexual fantasy is not only contentious, but can also be misleading. That is, as comparative studies have indicated (e.g., Looman, 1995), there is often little difference between the broad fantasy themes of sexual offenders, nonsexual offenders, and community samples, even with respect to deviant themes. By moving away from the notion of "deviant fantasy themes" future research may prove more fruitful in drawing distinctions between the fantasy themes evident in community samples, and those more "preparatory" fantasies often seen to accompany sexual offending (see Gee, Ward, \& Eccelston, 2003).

The second salient feature of the SFCM, which is a departure from existing research, is the distinction between two categories of offence-focused fantasy; that is, nonspecific offence fantasy and offence-specific fantasy. For those offenders who report engaging in offence-focused fantasy, nonspecific offence fantasies may be an important stepping-stone in the process of sexual offending. That is, similar to the disinhibiting effects of pornography (Cline, 1994; Hudson \& Ward, 1997), the recurrent use of nonspecific offence fantasy may provide the offender with a way of desensitizing himself to the offence themes present within the fantasy, a process which increases the likelihood of offending (Looman, 1995; Neidigh \& Tomiko, 1991; Ward \& Hudson, 1998a). The third significant feature of the SFCM is the existence of three distinct interpersonal foci (i.e., self, mutual, and other) within the relational subcategory of sexual fantasy. Although similar foci have been reported within an offender's cognitive distortions, (Ward et al., 1998; Ward, Louden, Hudson, \& Marshall, 1995), we believe that the SFCM is 
the first to acknowledge the presence of such foci within an offender's fantasies. The fourth salient feature, or strength, that emerged from the construction of the SFCM, was the development of a temporal dimension to sexual fantasy. Rather than the general assumption that sexual fantasy was specific to preoffence stages and related to the alleviation of negative affect, the current research suggests that sexual fantasies occur throughout the offence process, with different content and themes, depending on the stage of the offence chain.

There are a number of treatment implications that follow from the SFCM. The first arises out of the heterogeneity evident in the offenders' fantasies. Different sexual offenders report different levels of engagement in those sexual fantasies, both offence specific and nonoffence specific, which are related to their offence behavior. Therefore, there is a need to individually formulate cases. Secondly, and related to the first point, clinicians should note that the themes in the sexual fantasies of offenders are extremely diverse, and often depend on the phase of the offence process that the offender is in at the time. Third, if offenders can learn the importance of sexual fantasy across the offence process, it may put them in a better position to monitor their level of risk. Because of the difficulty offenders may have in identifying their emotional states (a commonly used trigger to signify danger of relapse) sexual fantasy can arguably provide the offender with the first clear signal to use appropriate coping strategies, an approach that has been successful with other disorders (e.g. Borkovec \& Ruscio, 2001). Finally, given the high proportion of participants who reported actively inhibiting all forms of sexual fantasy during their participation in treatment, we suggest that this form of thought suppression is unrealistic and may lead to paradoxical outcomes (Johnston, Ward, \& Hudson, 1997).

There are a number of limitations of this study, some of which are associated with the use of a qualitative methodology. Because a confirmatory sampleoften used in quantitative research-was not used, there is some difficulty in generalizing from the current participant sample, and also discounting researcher bias. This can be addressed in future research, using the hypotheses derived from this study. Future research could also consider targeting fantasies in offenders who have received treatment within programs differing in theoretical orientation to those in this study, as well as assessing the potential fantasies of those offenders who refuse to participate in treatment programs despite being eligible.

As this research constitutes a preliminarily step in the development of a comprehensive theory of sexual fantasy in sexual offending, the SFCM needs further scrutiny. First, there is a need to assess the saturation and intercoder reliability of the categories of the model. To achieve this, new interview protocols would need to be coded into the existing model by independent investigators. Second, cross-validation studies are required. For this process, independent investigators would need to collect new interview protocols from complementary samples. This would not only help to broaden the scope of the present model, but would also 
offset potential coding biases. Finally, studies investigating the generalization of the model to specific populations are needed.

\section{REFERENCES}

Arndt, W. B., Foehl, J. C., \& Good, F. E. (1985). Specific sexual fantasy themes: A multidimensional study. Journal of Personality and Social Psychology, 48, 472-480.

Badcock, R. (1997). Developmental and clinical issues in relation to offending in the individual. In J. L. Jackson \& D. A. Bekerian (Eds.), Offender profiling: Theory, research and practice (pp. 9-42). Chichester, England: Wiley.

Baumgartner, J. V., Scalora, M. J., \& Huss, M. T. (2002). Assessment of the Wilson Sex Fantasy Questionnaire among child molesters and nonsexual forensic offenders. Sexual Abuse: A Journal of Research and Treatment, 14, 19-30.

Borkovec, T. D., \& Ruscio, A. M. (2001). Psychotherapy for generalized anxiety disorder. Journal of Clinical Psychiatry, 62, 37-42.

Briere, J., \& Runtz, M. (1989). University males' sexual interest in children: Predicting potential indices of "pedophilia" in a nonforensic sample. Child Abuse and Neglect, 13, 65-75.

Briere, J., Smiljanich, K., \& Henschel, D. (1994). Sexual fantasies, gender, and molestation history. Child Abuse and Neglect, 18, 131-137.

Burgess, A. W., Hartman, C. R., Ressler, R. K., Douglas, J. E., \& McCormack, A. (1986). Sexual homicide: A motivational model. Journal of Interpersonal Violence, 1, 251-272.

Burgess, A. W., Hazelwood, R. R., Rokous, F. E., Hartman, C. R., \& Burgess, A. G. (1988). Serial rapists and their victims: Reenactment and repetition. Annals of the New York Academy of Science, 528, 277-295.

Carlson, E. R., \& Havelock-Coleman, C. E. (1977). Experimental and motivational determinants of the richness of an induced sexual fantasy. Journal of Personality, 45, 528-541.

Cline, V. B. (1994). Pornography effects: Empirical and clinical evidence. In D. Zillmann, J. Bryant, \& A. Huston Stein (Eds.), Media, children, and the family: Social scientific, psychodynamic, and clinical perspectives (pp. 229-247). Hillsdale, NJ: Erlbaum.

Crepault, E., Abraham, G., Porto, R., \& Couture, M. (1976). Erotic imagery in women. In R. Gemme \& C. C. Wheeler (Eds.), Progress in sexology (pp. 267-285). New York: Plenum.

Crepault, E., \& Couture, M. (1980). Men's erotic fantasies. Archives of Sexual Behavior, 9, 565-581.

Crimes Act (1958). Victoria, Australia.

Drieschner, K., \& Lange, A. (1999). A review of cognitive factors in the etiology of rape: Theories, empirical studies, and implications. Clinical Psychological Review, 19, 57-77.

Gee, D. G., Hudson, S. M., \& Ward, T. (2003). Psychological profiles of treated child sex offenders and those sexual offenders who refuse intervention despite being eligible. Manuscript in preparation.

Gee, D. G., Ward, T., Belofastov, A., \& Beech, T. (2003). The structural properties of sexual fantasies for sexual offenders. Manuscript in preparation.

Gee, D. G., Ward, T., \& Eccelston, L. (2003). The function of sexual fantasies for sexual offenders. Behavior Change, 20, 44-60.

Hazelwood, R. R., \& Warren, J. I. (1995). The relevance of fantasy in serial sexual crime investigation. In R. R. Hazelwood \& A. W. Burgess (Eds.), Practical aspects of rape investigation: A multidisciplinary approach (2nd ed., pp. 127-137). New York: CRC Press.

Henwood, K. L., \& Pidgeon, N. F. (1992). Qualitative research and psychological theorizing. British Journal of Psychology, 83, 97-111.

Hudson, S. M., \& Ward, T. (1997). Rape: Psychopathology and theory. In R. D. Laws \& W. O’Donohue (Eds.), Sexual deviance: Theory, assessment, and treatment (pp. 332-355). London: Guilford Press.

Hunt, M. (1974). Sexual behavior in the 70's. Chicago: Playboy Press.

Iwawaki, S., \& Wilson, G. D. (1983). Sex fantasies in Japan. Personality and Individual Differences, 4, 543-545.

Johnston, L., Ward, T., \& Hudson, S. M. (1997). Mental control and the treatment of sexual offending. Journal of Sex Research, 34, 121-130. 
Jones, J. C., \& Barlow, D. H. (1990). Self-reported frequency of sexual urges, fantasies and masturbatory fantasies in heterosexual males and females. Archives of Sexual Behavior, 19, 269-279.

Langevin, R., Lang, R. A., \& Curnoe, S. (1998). The prevalence of sex offenders with deviant fantasies. Journal of Interpersonal Violence, 13, 315-327.

Laws, D. R., Hudson, S. M., \& Ward, T. (2000). Remaking relapse prevention with sex offenders: A sourcebook. Thousand Oaks, CA: Sage.

Leitenberg, H., \& Henning, K. (1995). Sexual fantasy. Psychological Bulletin, 117, 469-496.

Lincoln, Y. S., \& Guba, E. G. (1985). Naturalistic inquiry. Beverly Hills, CA: Sage.

Looman, J. (1995). Sexual fantasies of child molesters. Canadian Journal of Behavioral Science, 37, 321-332.

Looman, J. (1997). Mood, conflict, and deviant sexual fantasies. In B. K. Schwartz (Ed.), The sex offender: Theoretical advances, treating special populations and legal developments (Vol. 3, Chap. 3, pp. 1-11). Kingston, NJ: Civic Research Institute.

Mace, M. (1998). Modelling the creative process: A Grounded Theory analysis of creativity in the domain of art making. Unpublished doctoral dissertation, University of Canterbury, Christchurch, New Zealand.

McCollaum, B., \& Lester, D. (1994). Violent sexual fantasies and sexual behavior. Psychological Reports, 75,742 .

McGuire, R. J., Carlisle, J. M., \& Young, B. G. (1965). Sexual deviations as conditional behavior: A hypothesis. Behavior Research and Therapy, 2, 185-190.

McMurran, H., Hodge, J., \& Hollin, C. R. (1997). Introduction: Current issues in the treatment of addictions and crime. In J. Hodge, H. McMurran, \& C. R. Hollin (Eds.), Addicted to crime (pp. 1-9). Chichester, England: Wiley.

Mednick, R. A. (1977). Gender-specific variances in sexual fantasy. Journal of Personality Assessment, $41,248-254$.

Meuwissen, I., \& Over, R. (1991). Multidimensionality of the content of female sexual fantasy. Behavior Research and Therapy, 29, 179-189.

Neidigh, L. W., \& Tomiko, R. (1991). The coping strategies of child sexual abusers. Journal of Sex Education and Therapy, 17, 103-110.

Person, E. S., Terestman, N., Myers, W. A., Goldberg, E. L., \& Salvadori, C. (1989). Gender differences in sexual behaviors and fantasies in a college population. Journal of Sex and Marital Therapy, 15, 187-198.

Pitcher, E. G., \& Prelinger, E. (1963). Children tell stories: An analysis of fantasies. New York: International University Press.

Pithers, W. D. (1990). Relapse prevention with sexual aggressors: A method for maintaining therapeutic gains and enhancing external supervision. In W. L. Marshall, D. R. Laws, \& H. E. Barbaree (Eds.), Handbook of sexual assault: Issues, theories, and treatment of the offenders (pp. 343-362). New York: Plenum.

Plaud, J. J., \& Bigwood, S. J. (1997). A multivariate analysis of the sexual fantasy themes of college men. Journal of Sex and Marital Therapy, 23, 221-230.

Prentky, R. A., Burgess, A. W., Rokous, F., Lee, A., Hartman, C., Ressler, R., et al. (1989). The presumptive role of fantasy in serial sexual homicide. American Journal of Psychiatry, 146, 887-891.

Qualitative Solutions and Research. (1998). QSR NUD*IST: Users Manual (Version 4). Melbourne: Author.

Reich, J. H. (1993). Prevalence and characteristics of sadistic personality disorder in an outpatient veterans population. Psychiatry Research, 48, 267-276.

Rennie, D., Phillips, J., \& Quartaro, G. (1988). Grounded theory: A promising approach to conceptualisation in psychology. Canadian Psychology, 29, 139-159.

Rokach, A. (1990). Content analysis of sexual fantasies of males and females. Journal of Psychology, $124,427-436$.

Singer, J. L. (1966). Daydreaming: An introduction to the experimental study of inner experience. New York: City College, City University.

Smith, D., \& Over, R. (1987). Male sexual arousal as a function of the content and the vividness of erotic fantasy. Psychophysiology, 24, 334-339.

Smith, D., \& Over, R. (1991). Male sexual fantasy: Multidimensionality in content. Behaviour Research and Therapy, 29, 267-275. 
Storms, M. D. (1981). A theory of erotic orientation development. Psychological Review, 88, 340-353.

Strauss, A., \& Corbin, J. (1990). Basics of qualitative research: Grounded Theory procedures and techniques. Newbury Park, CA: Sage.

Sue, D. (1979). Erotic fantasies of college students during coitus. Journal of Sex Research, 15, 299-305.

Templeman, T. L., \& Stinnett, R. D. (1991). Patterns of sexual arousal and history in a "normal" sample of young men. Archives of Sexual Behavior, 20, 137-150.

Wagman, M. (1967). Sex differences in types of daydreams. Journal of Personality and Social Psychology, 7, 329-332.

Ward, T. (2000). Relapse prevention: A critique and reformulation. Journal of Sexual Aggression, 5 , 59-77.

Ward, T., Fon, C., Hudson, S. M., \& McCormack, J. (1998). A descriptive model of dysfunctional cognitions in child molesters. Journal of Interpersonal Violence, 13, 129-155.

Ward, T., \& Hudson, S. M. (1998a). A model of the relapse process in sexual offenders. Journal of Interpersonal Violence, 13, 700-725.

Ward, T., \& Hudson, S. M. (1998b). The construction and development of theory in the sexual offending area: A metatheoretical framework. Sexual Abuse: A Journal of Research and Treatment, 10, 47 63.

Ward, T., \& Hudson, S. M. (2000). Sexual offenders implicit planning: A conceptual model. Sexual Abuse: A Journal of Research and Treatment, 12, 189-202.

Ward, T., Louden, K., Hudson, S. M., \& Marshall, W. L. (1995). A descriptive model of the offence chain in child molesters. Journal of Interpersonal Violence, 10, 452-472.

Ward, T., \& Siegert, R. J. (2002). Towards a comprehensive theory of child sexual abuse: A theory knitting perspective. Psychology, Crime \& Law, 9, 319-351.

Wilson, G. D. (1988). Measurement of sexual fantasy. Sexual and Marital Therapy, 3, 45-55.

Wilson, G. D., \& Lang, R. J. (1981). Sex differences in sexual fantasy patterns. Personality and Individual Differences, 2, 343-346.

Wilson, L., Ward, T., \& Bakker, L. (1999). A qualitative model of relapse in disqualified drivers. Behavior Change, 16, 111-126.

Zimmer, D., Borchardt, E., \& Fischle, C. (1983). Sexual fantasies of sexually distressed and nondistressed men and women: An empirical comparison. Journal of Sex and Marital Therapy, 9, $38-50$. 